\title{
Sensorless Speed Estimation in Wound Rotor Induction Machines by Spectral Search of the Stator Phase Power Signal
}

\author{
K. Tshiloz ${ }^{1}$, D. Vilchis-Rodriguez ${ }^{1}$, S. Djukanović ${ }^{2}$, N. Sarma ${ }^{1}$, S. Djurović ${ }^{1 *}$ \\ ${ }^{1}$ Power Conversion Group, The University of Manchester, Sackville Street Building, \\ Manchester, UK \\ ${ }^{2}$ Faculty of Electrical Engineering, University of Montenegro, 20000 Podgorica, Montenegro \\ ssinisa.durovic@manchester.ac.uk
}

\begin{abstract}
:
This paper investigates the feasibility of utilising the stator phase power signal to establish sensorless speed estimation schemes in wound rotor induction machines (WRIMs). To this end the authors derive and validate closed form expressions defining the possible power signal spectral content containing rotor speed information. Based on these, two novel sensorless speed estimation techniques are proposed: the first enables supply frequency independent speed estimation in WRIM extended slip applications, while the second facilitates estimation in a wide operating speed range for scalar controlled WRIM applications based on a sliding-window search of the power spectrum. The proposed techniques are underpinned by a dichotomous search enabled spectral processing algorithm and shown to deliver an increase in attainable real-time estimation rate without compromising estimation accuracy. The performance of reported schemes is assessed and validated in real-time laboratory experiments.
\end{abstract}

\section{Introduction}

Sensorless speed estimation in induction machines (IMs) has long presented an attractive proposition for eliminating the need for physical velocity sensors and thus avoiding the associated reliability and cost issues [1-8]. Various IM sensorless speed estimation techniques have been proposed in literature that can largely be classified into two major groups: the spectral search based (SSB) [1-6] and the model-observer based (MOB) methods [7-8]. The SSB sensorless techniques are of particular interest in this work as they generally provide higher immunity to knowledge of machine parameters when compared to MOB schemes.

The SSB methods for cage rotor induction machines (CRIMs) are predominantly based on utilising spectral components present in the stator current signals to achieve real-time detection and tracking of rotor speed. The frequencies of the rotor slot and eccentricity harmonics were extracted in [1, 4-6] using maximum entropy spectral estimation, or interpolation method, in combination with the Discrete Fourier transform (DFT). The reported steady-state maximum estimation error of these methods is up to $\approx 1 \%$, for which the reported achievable estimation rate is $\approx 3$ estimates/second [4]. The Hilbert transform combined with DFT and interpolation was employed in [5] to track eccentricity harmonics of an inverter-fed CRIM. The reported estimation rate required to achieve a steady-state maximum error below $\approx 1.5 \%$ with this technique is $\approx 2$ estimations per second. The Chirp-Z transform was proposed in [6] to track the rotor slot 
harmonics of a CRIM operating in the nominal speed range; $\mathrm{a} \approx 0.163 \%$ maximum estimation error was reported at a rate of $\approx 5$ estimates/second. The SSB speed estimation performance limitations during CRIM transient operation have been less researched in existing literature. A common limitation of reported SSB estimation schemes is that, in inverter-fed scalar controlled CRIM applications, these are largely constrained to effective operation in a relatively narrow operating speed range, which challenges their practical application potential. Another impediment stems from the restraints in the execution time of the required spectral search routines which inherently limit the attainable real-time estimation rates.

WRIMs have been reported to exhibit strong spectral signatures in stator electrical signals [9-12]. These machines, commonly used in the wind, cement, mining and water industries, are yet to receive significant attention where SSB sensorless speed estimation techniques are concerned [13]. Efforts have been made to utilise the accessibility of WRIM rotor windings to achieve sensorless speed estimation based on rotor voltage zero-crossing detection [13-14]. However, in addition to introducing the need for additional sensing this method can be compromised in no-load and partial-load conditions.

This paper investigates the potential for utilisation of the readily available stator phase power signal to enable SSB sensorless speed estimation techniques in WRIMs. Rotor speed estimation for WRIM operation in extended slip applications such as found in type-II topology OptiSlip and FlexSlip wind turbine (WT) drives [15-16] and operation with $\mathrm{V} / \mathrm{Hz}$ scalar control such as can be found in industrial mill, crane or hoist systems [17] is researched. To this end, a theoretical investigation of WRIM phase power signal spectrum is first undertaken to derive closed-form expressions that enable the correlation of individual spectral frequencies to rotor speed. These are validated in harmonic model and experimental tests for an investigated $7.5 \mathrm{~kW}$ industrial WRIM design and allow for identification of spectral components suitable for enabling sensorless estimation schemes. Novel, phase power signal SSB, sensorless speed estimation algorithms are then separately proposed for WRIM extended slip applications and WRIM open-loop controlled schemes. A new speed estimation algorithm with no requirement for supply frequency monitoring is proposed for the extended slip mode of operation. An innovative slidingwindow SSB estimation algorithm aimed at scalar controlled WRIM operation is reported that facilitates effective real-time speed estimation in a wide operating speed range. The real-time power signal spectral search technique developed to underpin the presented algorithms employs a dichotomous search based routine [18-20] to deliver an improvement on the reported attainable real-time estimation rates. The proposed algorithms are shown to provide reliable performance at high estimation rates in a range of steady-state and transient real-time tests on the laboratory machine. 


\section{WRIM Phase Power Signal Spectrum}

\subsection{Theory}

This section presents an analytical analysis of a three-phase $p$-pole pair WRIM stator phase power signal spectral content. Higher order supply harmonics are not considered as dominant magnitude spectral components in the power signal spectra that originate from the fundamental supply harmonic [21-23] are of interest in this analysis. While derivations are performed for a general case of a symmetrical machine operating with or without supply unbalance, machine operation with supply unbalance is of foremost interest in this work as this operating scenario is characteristic of practical applications. A general expression defining the stator phase voltage fundamental can be written as:

$$
v=V_{M}^{m} \cos (m \omega t+\gamma)
$$

where: $V_{M}^{m}$ is the $m$-th sequence voltage peak, $\omega$ is the supply angular frequency $(\omega=2 \pi f$, where $f$ is the fundamental supply frequency), $m$ is defined as the unbalance index that can take a positive and/or a negative unity value (i.e. $m=1$ for a balanced and $m= \pm 1$ for an unbalanced three-phase supply) and, for the sake of generality, $\gamma$ represents an arbitrary phase shift.

The slotting effect induced inter-harmonic content typically found in the stator current spectra of WRIMs supplied by fundamental-only excitation can be described by [9, 21]:

$$
i=I_{M}^{k, n} \cos \left[(1 \pm 6 k(1-s)) n \omega t+\varphi^{k, n}+\gamma\right]
$$

where: $I_{M}^{k, n}$ is the $k, n$-th component's peak value, $s$ is the fundamental fractional slip, $k=0,1,2,3 \ldots$ relates to air-gap field pole-pair numbers and $\varphi^{k, n}$ is the $k, n$-th power factor angle. $n$ is defined as the unbalance index and can take a positive and/or a negative unity value depending on supply balance, identical to the definitions stated for $m$.

The formula defining the power signal, $P$, can now be established by multiplication of (1) and (2):

$$
\begin{aligned}
P & =i v \\
& =\frac{V_{M}^{m} I_{M}^{k, n}}{2}\left\{\cos \left[((1 \pm 6 k(1-\mathrm{s})) n+m) \omega t+\varphi^{k, n}+2 \gamma\right]+\cos \left[((1 \pm 6 k(1-\mathrm{s})) n-m) \omega t+\varphi^{k, n}\right] .\right.
\end{aligned}
$$


The above expression enables a general characterisation of the possible spectral frequencies in the stator phase power signal of a three-phase $p$-pole WRIM:

$$
f_{\text {power }}=|n \pm 6 k n(1-s) \pm m| f \text {. }
$$

Substituting the constraints for a practical case of interest that involves symmetrical machine operation with unbalanced supply, i.e. $n= \pm 1, m= \pm 1, k=0,1,2 \ldots$, in (4) yields the expressions defining two subsets of possible frequencies in the power spectrum:

$$
\begin{aligned}
& f_{\text {power }}=|6 k(1-s)| f, \\
& f_{\text {power }}=|2 \pm 6 k(1-s)| f .
\end{aligned}
$$

The possible spectral content of the power signal will not change when the machine is operating with a balanced supply ( $n=1, m=1$ and $k=0,1,2 \ldots$ in (4)) and remains defined by (5) and (6). Introducing the fundamental slip relationship, $(1-s)=n_{r} / n_{s}$, where $n_{r}$ is the rotor and $n_{s}$ is the synchronous speed in rpm, allows for a clearer definition of the power spectral content and its direct relation to the rotor speed and the supply frequency:

$$
\begin{aligned}
& f_{\text {power }}=k p \frac{n_{r}}{10}, \\
& f_{\text {power }}=\left|2 f \pm k p \frac{n_{r}}{10}\right| .
\end{aligned}
$$

More importantly, the power signal frequency subset given by (7) is seen to be supply frequency independent and contains a harmonic series of $p n_{r} / 10$. While supply frequency related components given by (8) may also exist in the spectrum, the subset defined by (7) is of particular interest in this work as it can, in principle, enable rotor speed estimation without knowledge of supply frequency.

\subsection{Phase Power Spectrum Model Study}

To establish the validity of derivations in 2.1 and illustrate the spectral content of a typical WRIM power signal, a model study of the examined industrial four-pole 50Hz WRIM design's (full details in 
section 4.1) power spectrum when operating in the nominal speed range is reported in this section. The spectrum was examined in the bandwidth of up to $\approx 1000 \mathrm{~Hz}$ to include spectral content of interest in this work.

The model study was facilitated by a coupled-circuit dynamic model based on the principles of generalised harmonic analysis [9, 24-25]. The model accounts for higher order field effects and can represent spectral signature of electrical unbalance. Detailed operational and design data of the investigated WRIM were used as model inputs to numerically emulate the behavior of the laboratory machine. The calculations assume short-circuited rotor windings and stator windings supplied from a mono-component, fundamental-only, three-phase supply. The power spectra calculated for operation at no-load and full-load conditions within the nominal generating range are shown in Figs. 1a-b. To illustrate the spectral effects of supply unbalance two separate simulations were undertaken for each considered load level assuming operation with and without unbalance, and the results superimposed in the figures. The supply unbalance magnitude was set to $\approx 3 \%$ in relevant calculations, matching that measured during subsequent laboratory experiments.

The results show that the power spectrum contains a number of clearly defined components. These can be calculated from the knowledge of rotor speed with the appropriate values of $k$ and $f$, using the expressions in (7) for the supply frequency independent components and (8) for the components at frequencies related to the fundamental. The predicted frequency values and the corresponding equation number and $k$ value are shown in the figures and validate the expressions derived in 2.1. Excluding the double supply frequency component, each observed frequency contains information on rotor speed and will inhabit a clearly defined narrowband bounded by the individual component's frequency values for noload and full-load operation, $f_{\text {min }}^{k}$ and $f_{\max }^{k}$, respectively. The boundaries of the narrowbands encompassing individual $k$-th order harmonics defined by (7) are directly proportional to operating speed and are identified by vertical dotted lines in Fig. 1b for illustration purposes. These are of particular interest in this work as, assuming that a narrowband window maximised by a $k$-th order harmonic can be identified in a practical WRIM, it can be utilised to enable supply frequency independent sensorless speed estimation. 

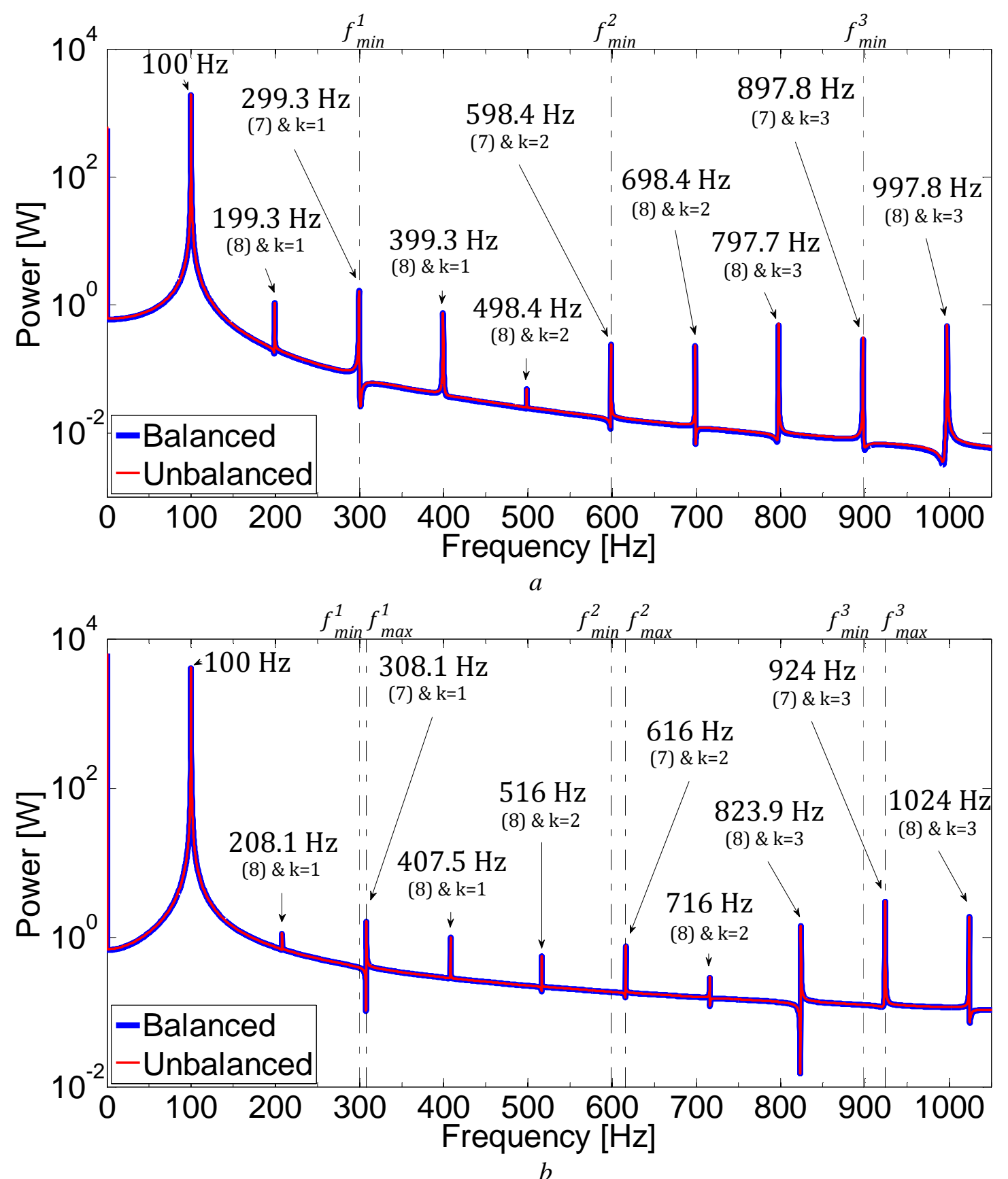

Fig. 1: Predicted Phase power spectrum, nominal operating region

a No-load $(\approx 1496 \mathrm{rpm})$

b Full load $(\approx 1540$ rpm $)$ 


\section{Proposed Sensorless Speed Estimation Method}

\subsection{Speed Detection Algorithm}

The general principles of the proposed speed estimation algorithm can be defined based on the discussion in section 2. The algorithm surveys a phase power signal narrowband window maximised by a $k$-th order frequency independent power harmonic defined by (7); a suitable power signal window to be searched is determined from tests on an examined practical WRIM design. The boundaries of the searched narrowband $\left(\approx f_{\min }^{k}, f_{\max }^{k}\right)$ are determined from $(7)$ based on the machine operating range limits, i.e. are formed by the no-load and full-load spectral co-ordinates of the tracked power harmonic. Real-time tracking of the $k$-th power harmonic frequency, $f_{\text {Tracked }}^{k}$, enables direct estimation of the rotor speed based on (7), i.e. $n_{r}=10 f_{\text {Tracked }}^{k} / \mathrm{kp}$. The proposed speed detection procedure is summarised in the flowchart in Fig. 2a.

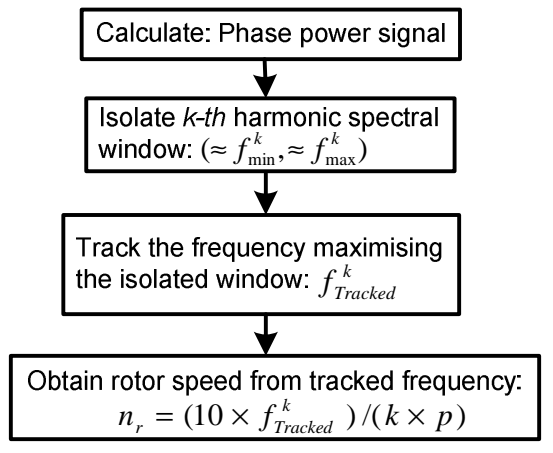

$a$

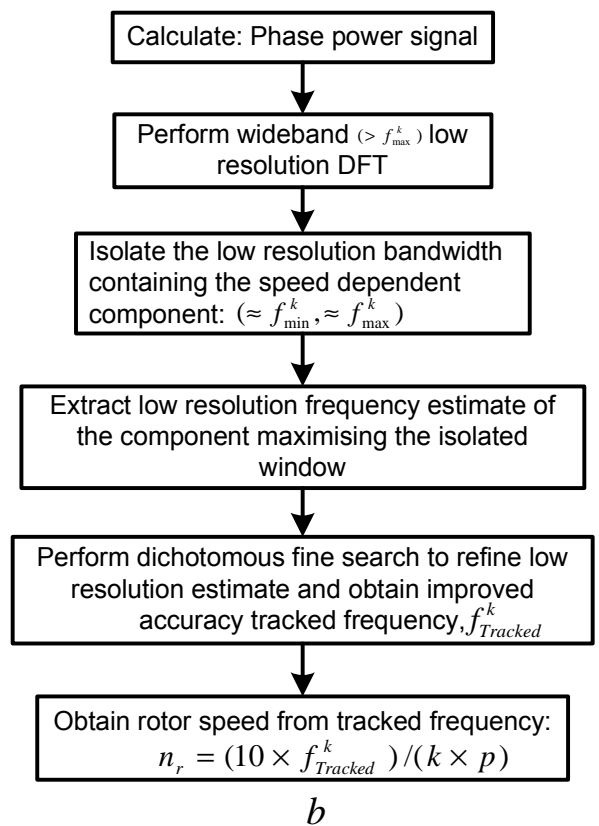

Fig. 2: Speed estimation algorithm

a General structure

b Full dichotomous search enabled algorithm structure

\subsection{Time-frequency Analysis}

The effectiveness of the proposed SSB algorithm in enabling real-time speed estimation will largely be determined by the capability of the utilised real-time frequency tracking technique. For this purpose the time-frequency analysis employed to underpin the proposed algorithm utilises a dichotomous search method [18-19], particularly suitable for real-time applications with constraints in attainable spectral 
resolution. The general principles of dichotomous search application for real-time frequency tracking in electrical machines were presented in [20] and are applied in this section on the phase power signal.

The dichotomous search algorithm comprises an initial, coarse search step followed by the final, iterative, fine search step [18]. The coarse search calculates the analysed signal's periodogram using an Lsamples long DFT with a relatively low frequency resolution $\Delta f$, and identifies the frequency of the maximum component in the resulting spectrum, $f_{\max }$. A fine search iterative procedure is then undertaken that adjusts the $f_{\max }$ estimation towards the larger of the two adjacent DFT coefficients at either side of the identified peak at $f_{\max }$. A new DFT coefficient is then calculated at a midpoint frequency between the original peak and the larger adjacent DFT coefficient. The position of the new DFT yields an improved frequency estimation compared to that obtained in the initial step. The fine search is repeated $Q$ times to

optimize the refinement of the obtained frequency estimation. The steps constituting the dichotomous search based power harmonic frequency estimation can be described as follows:

Step 1. Coarse search

Calculate the phase power signal periodogram $P(f)$ with resolution $\Delta f$ and identify its maximum position $f_{\max }$. Denote $P_{0}=P\left(f_{\max }\right)$. Calculate $P(f)$ at points $f_{\max } \pm \Delta f / 2$, i.e.

$$
P_{-1}=P\left(f_{\max }-\Delta f / 2\right) \text { and } P_{1}=P\left(f_{\max }+\Delta f / 2\right) \text {. }
$$

\section{Step 2. Iterative fine search}

Iterate $Q$ times:

$\Delta f=\Delta f / 2$

if $P_{1}>P_{-1}$ then $P_{-1}=P_{0}$ and $f_{\text {max }}=f_{\text {max }}+\Delta f$

else $P_{1}=P_{0}$ and $f_{\max }=f_{\max }-\Delta f$.

calculate $P\left(f_{\max }\right)$ and set $P_{0}=P\left(f_{\max }\right)$.

The final frequency estimation is the $f_{\max }$ value obtained in the $Q$-th iteration of the fine search step, and, in this application, provides the high accuracy real-time value of the tracked power harmonic frequency,

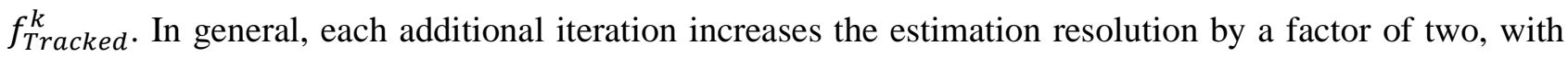
typical $Q$ values reported to provide optimal accuracy levels being > 10 [18-19].

The dichotomous search power harmonic frequency estimation is incorporated into the general algorithm in Fig. 2a to form the full, dichotomous routine enabled, sensorless speed estimation scheme. The full algorithm executes real-time frequency tracking of the $k$-th power harmonic within the searched narrowband window boundaries $\left(\approx f_{\text {min }}^{k}, f_{\text {max }}^{k}\right.$ ) determined from $(7)$ based on the machine operating slip 
range. The proposed full algorithm is summarised in a flowchart shown in Fig. $2 \mathrm{~b}$ and comprises the following general steps:

1) Perform a low resolution DFT in a set bandwidth $\left(>f_{\max }^{k}\right)$, constant duration time window of the power signal.

2) Extract the frequency maximising the low resolution narrowband $\left(\approx f_{\min }^{k}, f_{\max }^{k}\right)$ to obtain a coarse estimate of the tracked power harmonic's frequency.

3) Execute dichotomous iterative fine search on the extracted coarse frequency estimate to obtain improved accuracy estimation of the tracked power harmonic frequency, $f_{\text {Tracked }}^{k}$.

4) Utilise the value of $f_{\text {Tracked }}^{k}$ to obtain real-time rotor speed estimation based on (7)

\section{System Implementation, Experimental Results and Discussion}

\subsection{Test System Description}

The experimental work was performed on a $7.5 \mathrm{~kW}$, three-phase, 4-pole, $50 \mathrm{~Hz}$ star-connected VEM160M4 WRIM driven by a speed controlled DC motor. The DC motor speed was controlled to follow a desired load profile with a DC drive controller. The test machine rated slip is $s \approx 0.026$ and it can be operated in the nominal speed range by short circuiting the rotor and supplying the stator directly from the grid. In order to emulate the operating range of WT extended slip WRIM drives, a 10\% slip extension can be achieved by connecting an external three-phase resistive bank $(\approx 0.5 \Omega /$ phase $)$ to the rotor windings. The WRIM can also be operated in open-loop $\mathrm{V} / \mathrm{Hz}$ control mode, with a pre-programmed excitation profile provided by a commercial programmable power supply unit (PSU). The test-rig schematics showing the utilised rig configurations for the two examined modes of WRIM operation are respectively shown in Fig. 3a and Fig. 3b, while a photograph of the laboratory system is provided in Fig. 3c. The PSU can provide output frequencies in the range of $16-1000 \mathrm{~Hz}$ and operates at a fixed switching frequency of $\approx 3.75 \mathrm{kHz}$. WRIM stator current and voltage signals are measured using an LEM-LA305-S current and an LEM-LV25-600 voltage transducer. The rotor speed was measured using a 1024ppr incremental encoder. Current, voltage and encoder output signals were synchronously processed using an NI-9024 cRIO realtime controller platform.

The sensorless speed estimation algorithm proposed in Fig. $2 b$ is executed on the cRIO controller in two interlinked procedures following the principles presented in [20]: the power signal data collection and DFT processing performed on the FPGA module and the execution of the spectral search algorithms 
containing the coarse and the fine search routines hosted on the real-time module. This was achieved by developing appropriate LabVIEW virtual instrument (VI) code. The FPGA VI was developed to first establish the phase power signal by multiplication of the sensed current and voltage signals, then execute a $2^{n}$ data point power signal DFT in consecutive, non-overlapping, constant length Hanning windows, and finally perform the transfer of the measured time domain and calculated frequency domain power signal data to the cRIO controller, for further processing within each consecutive time window. The developed controller VI first isolates the bandwidth containing the rotor speed information, $\left(\approx f_{\min }^{k}, f_{\max }^{k}\right)$, and subsequently executes the real-time tracking of a known speed-dependent spectral component, $f_{\text {Tracked }}^{k}$, according to the estimation algorithm proposed in Fig. 2. Fig.3d shows a simplified schematic of the realtime algorithm's practical implementation.

The maximum real-time estimation rate provided by the dichotomous algorithm that can deliver a maximum real-time estimation error below $1 \%$ was identified in steady-state and transient estimation tests to be $\approx 10$ estimates/second. Consequently, the stator current and voltage were monitored with a sampling frequency of $\approx 2.56 \mathrm{kHz}$ to suit the constraints of the real-time platform DFT routine ( $2^{8}$ point). Real-time estimation was achieved by first executing a coarse search with a consecutive DFT window length of $2^{8}$ data points (i.e coarse search resolution of $\Delta f \approx 10 \mathrm{~Hz}$ ); this was followed by a fine search step executing a $Q=100$ iteration real-time dichotomous search routine for each successive window to optimise the coarse search estimation error [20]. The real-time execution time of a single window DFT+dichotomous algorithm search was measured as $\approx 0.326 \mathrm{~ms}$ for the considered iteration number at $\approx 10$ estimates/second rate and compares favourably to the applied DFT window duration of $\approx 0.1 \mathrm{sec}$ at this estimation rate.
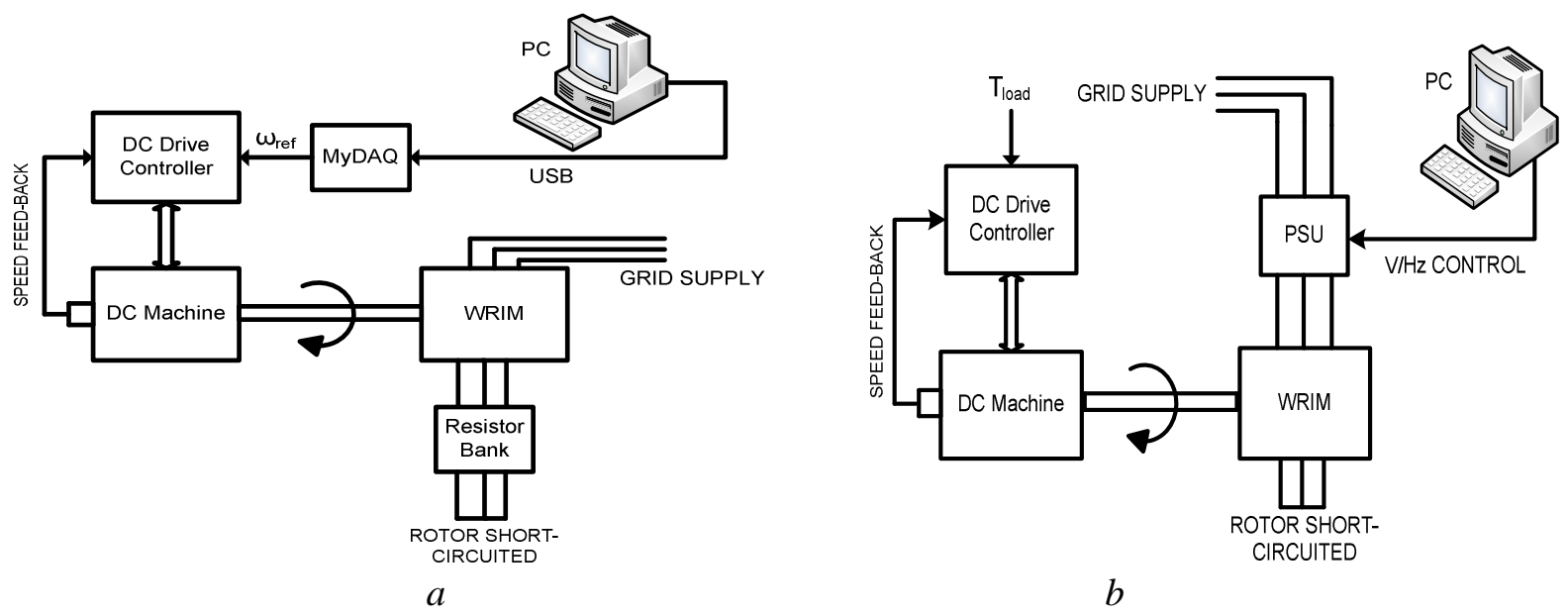


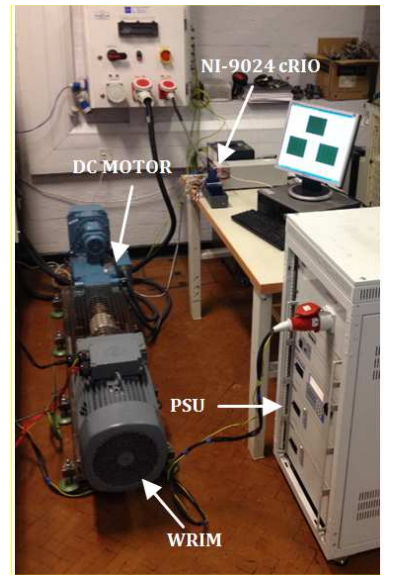

C

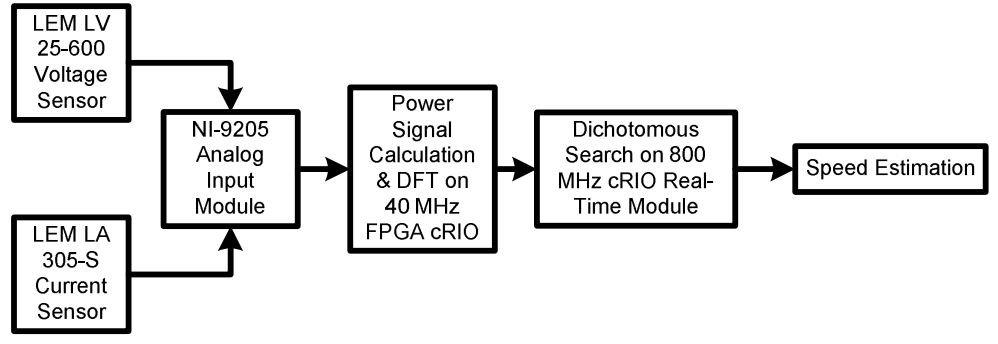

$d$

Fig. 3: Test rig layout

a Extended slip range operating mode schematics

b Open-loop $\mathrm{V} / \mathrm{Hz}$ controlled operating mode schematics

c Laboratory test-rig

d Simplified block diagram showing real-time algorithm's practical implementation

\subsection{Phase Power Spectrum Analysis in the Nominal Generating Region}

In order to validate the findings reported in section 2 and asses their practical manifestation an experimental study of the laboratory WRIM's phase power signal spectrum was performed for no-load and full-load generating conditions. The measured power spectra, obtained for the laboratory machine operating with a short-circuited rotor and a grid supplied stator are shown in Fig. 4a-b and facilitate a direct comparison with model results in Fig. 1a-b.

The inevitable presence of supply time-harmonic effects primarily results in pronounced magnitudes at frequencies equal to multiple integers of the fundamental in the measurements [21-22]. The fundamental supply induced spectral content defined by (7) and (8) is clearly present in the measurements for loaded operation and matches the model predictions in Fig. 1; the measured frequency values along with the corresponding equation number and $k$ value are identified in Fig. 4 and validate the equations derived in (7) and (8). During no-load operation, where $n_{r} \approx n_{S}$, the components defined by (7) and (8) will be at frequencies near those of supply harmonics and may therefore be amalgamated with these, where pronounced supply harmonics are present. However, the higher order power components given by (7) and (8) will generally be manifested at higher bandwidths and therefore intrinsically less susceptible to supply harmonic interference [26]. For the investigated WRIM design, the $k=3$ component in (7) is clearly present in the measured spectrum at a significantly higher level than the adjacent supply harmonic related component at $\approx 900 \mathrm{~Hz}$, including no-load conditions. The boundaries of harmonic windows containing individual power harmonics are shown in Fig. $4 \mathrm{~b}$ for illustration purposes. 

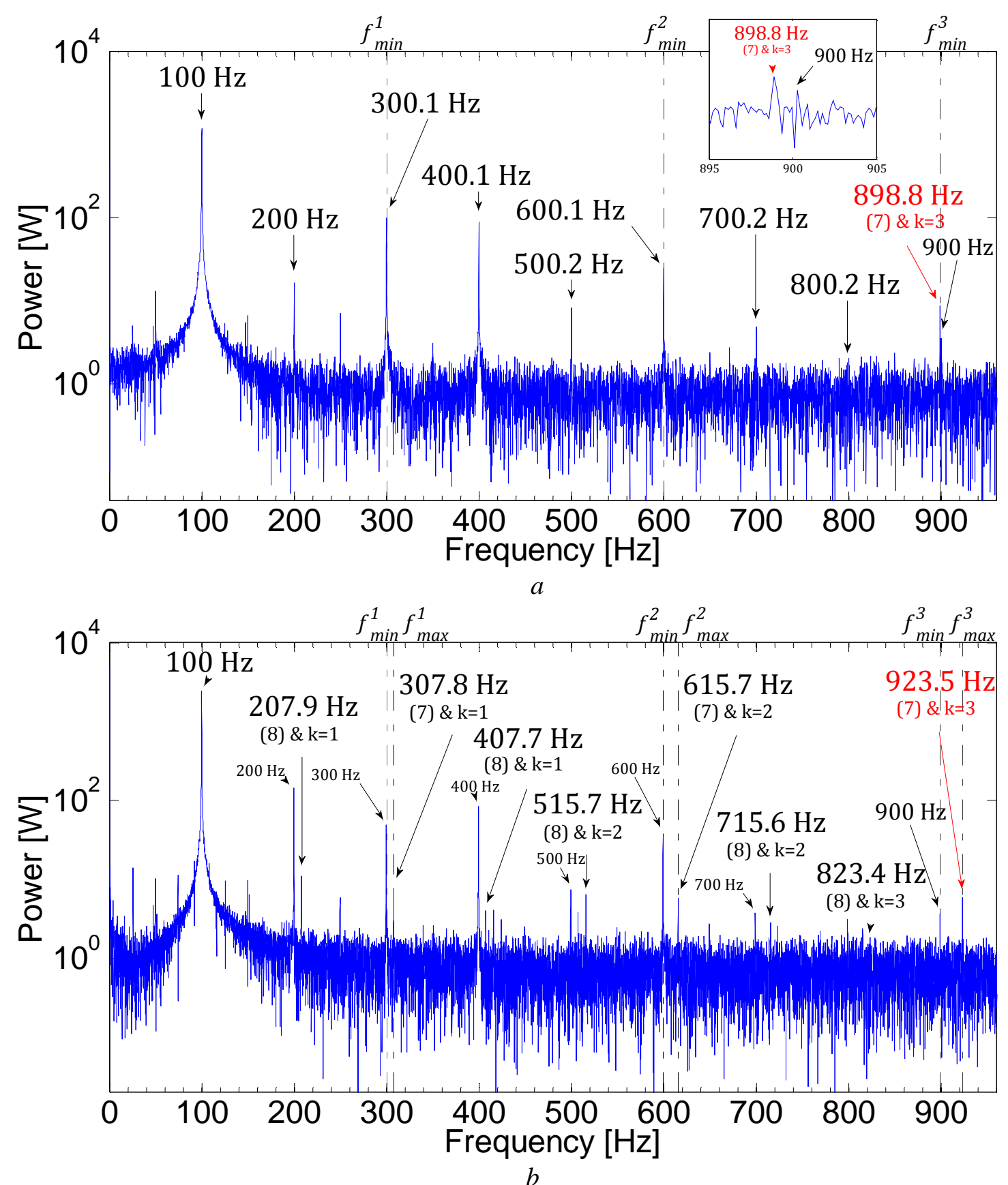

Fig. 4: Phase power spectrum, nominal operating region a Measured, no-load $(\approx 1496 \mathrm{rpm})$

b Measured, full load $(\approx 1540 \mathrm{rpm})$

\subsection{Real-time Speed Estimation for Extended Slip Operation}

4.3.1 Power Spectrum Analysis: The power spectrum for grid supplied WRIM operation in the -10\% slip range typical of WT Type-II WRIM drives [15-16] is examined in this section with a view to identifying 
spectral components that could facilitate sensorless speed estimation. The power spectra recorded in a $\approx 0$ $1000 \mathrm{~Hz}$ bandwidth at no-load and full-load are shown in Fig. 5a-b. The spectral content patterns observed in sections 2 and 4.2 are seen to remain valid for the extended slip operation. The supply frequency independent spectral components defined by (7) are clearly identifiable in the loaded conditions, and the boundaries of spectral windows containing individual harmonics shown in Fig. 5b. While most frequencies in the investigated bandwidth are amalgamated with supply harmonic effects during no-load conditions the $k=3$ component in $(7)(\approx 892.9 \mathrm{~Hz}$ in Fig.5a) is seen to be manifested at a considerably stronger magnitude level than the adjacent supply harmonic related component $(\approx 900 \mathrm{~Hz})$. This suggests that, while other adequate candidates exist in the power spectrum, the $k=3$ supply frequency independent harmonic can be deemed most suitable for enabling SSB speed estimation for extended slip operation of the investigated WRIM design.

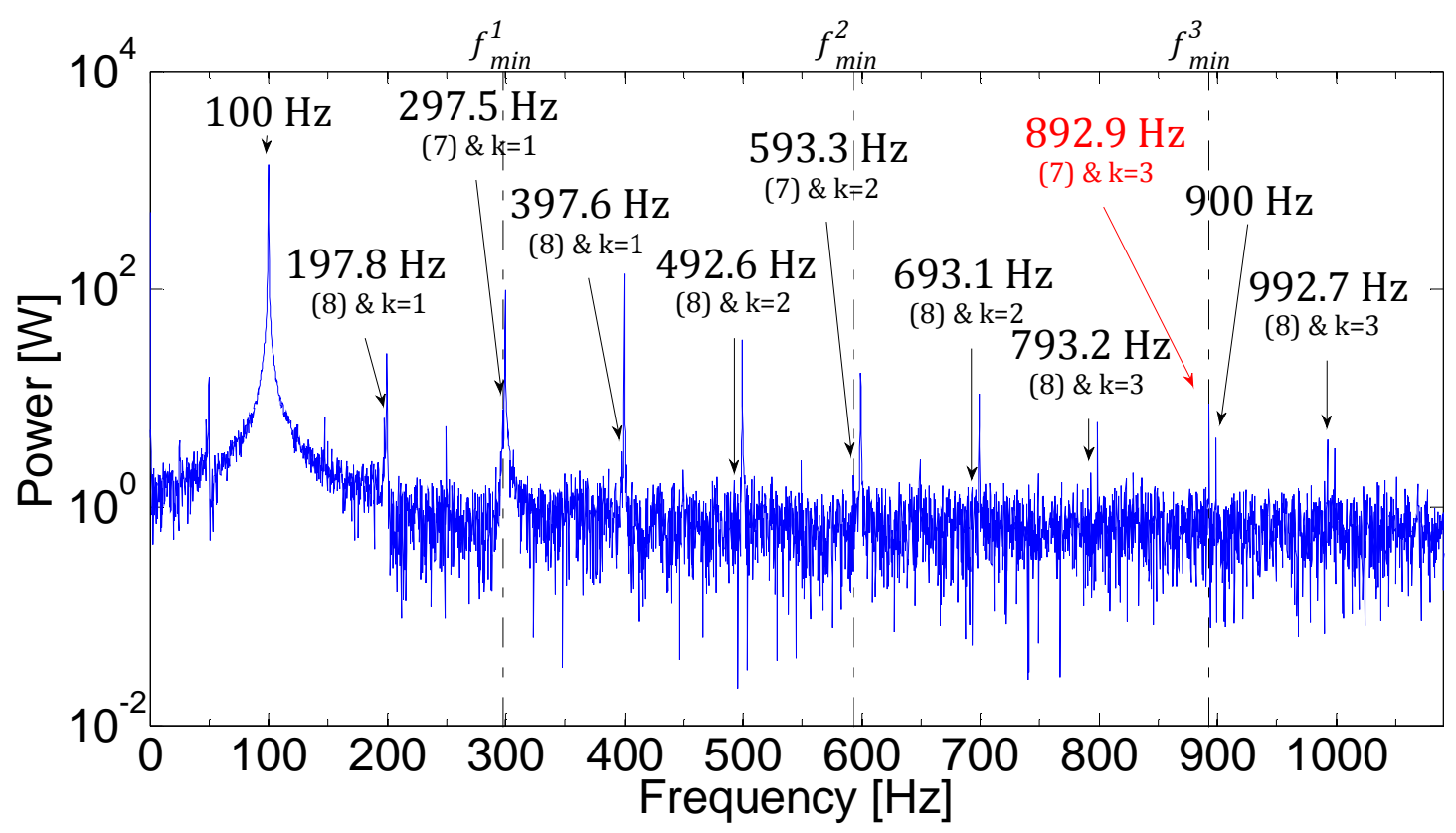

$a$ 


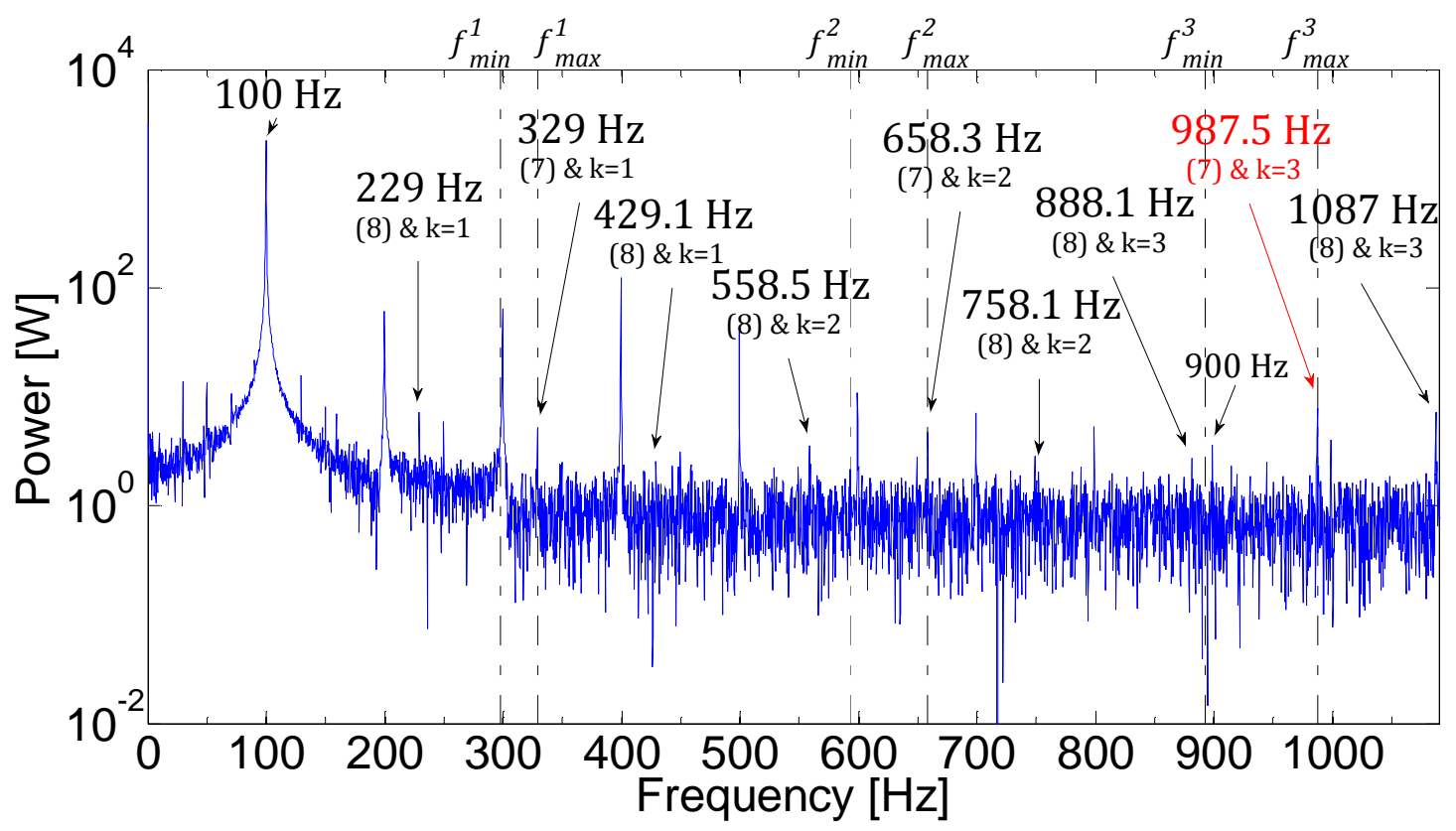

$b$

Fig. 5. Measured power spectrum, extended slip operation

a No-load $(\approx 1489$ rpm $)$

b Full load $(\approx 1650 \mathrm{rpm})$

For generating operation in the $-10 \%$ slip range the bandwidth containing the $k=3$ component will be relatively narrow and can be calculated using (7) to encompass the $\approx 900-990 \mathrm{~Hz}$ frequency band. This narrowband was subjected to detailed experimental investigation for a larger number of gradually increasing steady-state load points, Fig. 6. These measurements illustrate that the $k=3$ harmonic maximises the examined narrowband and that its extraction could therefore facilitate effective speed estimation requiring no knowledge of supply frequency. It should be noted that speed estimation from the no-load spectrum is of less significance in WT drives as turbine generators are energised at higher than zero slips and usually do not operate at no-load conditions [27]. Power signal narrowbands containing other components given by (7) and, assuming knowledge of supply frequency is available, (8), could therefore also be of interest for enabling sensorless schemes for extended-slip operation, but are not investigated in this work for the sake of brevity. 

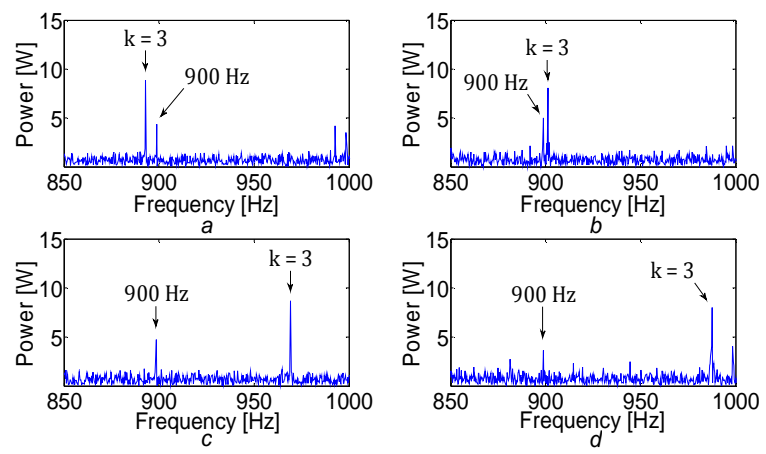

Fig. 6: Measured phase power signal narrowband spectrum at 0\%, 5\%, 50\% and 100\% load, extended slip operation a No-load b $5 \%$ load c $50 \%$ load d $100 \%$ load

4.3.2 Real-time Results for Steady-state Operation: The algorithm proposed in Fig. 2b was employed to obtain real-time speed estimation of the laboratory WRIM based on utilising the $k=3$ supply frequency independent power harmonic. The real-time speed estimation performance was first investigated for steady-state operation within the extended slip range. The estimated speed was recorded synchronously with the encoder measured speed in tests to enable reliable benchmarking of the estimation algorithm. The maximum and average estimation errors with respect to encoder measurement are shown in percent of the encoder measured speed for each examined operating scenario. The dichotomous search enabled estimation performance improvement is evaluated by comparing the synchronously obtained speed estimation obtained by using the coarse search (i.e. DFT) algorithm only and the proposed coarse+fine search method.

The steady-state estimation results obtained for different load points are shown in Fig. 7. The data demonstrate a close agreement between encoder measurements and dichotomous search estimation. In comparison with the DFT only obtained speed estimation the dichotomous search algorithm is measured to considerably improve the estimation accuracy, resulting in a $\approx 68 \%$ reduction in average estimation error at $\approx 10$ estimates/second rate. Obtaining a similar level of estimation error reduction based on utilising the DFT algorithm only would require a multifold increase in spectral resolution which would consequently result in an impractical multifold decrease in the attainable estimation rate. Furthermore, unlike the conventional SSB sensorless estimation schemes [1-6], no real-time monitoring of supply frequency is required to establish the proposed estimation scheme. There is hence no additional estimation variability or error that can be introduced by existing supply frequency measurement inaccuracy originating from 
frequency variations common in practical systems. The estimation error measured in real-time tests executing coarse search only and coarse+fine search routines is summarised in Table 1.

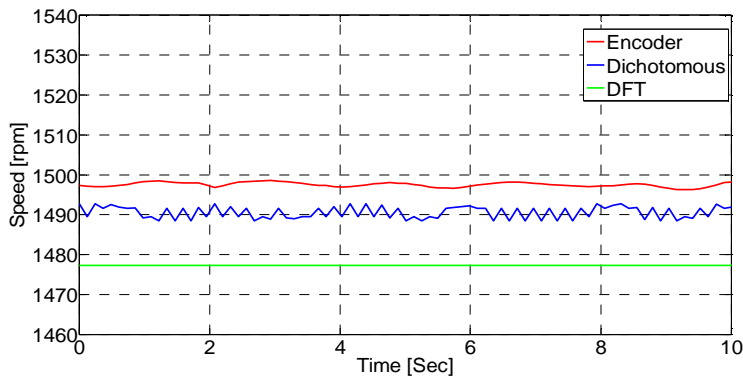

$a$

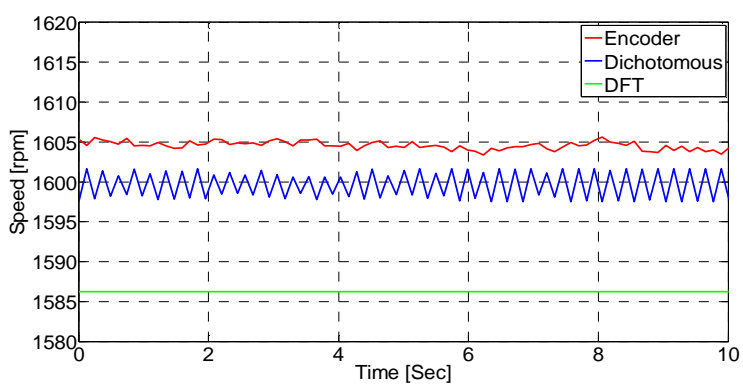

$c$

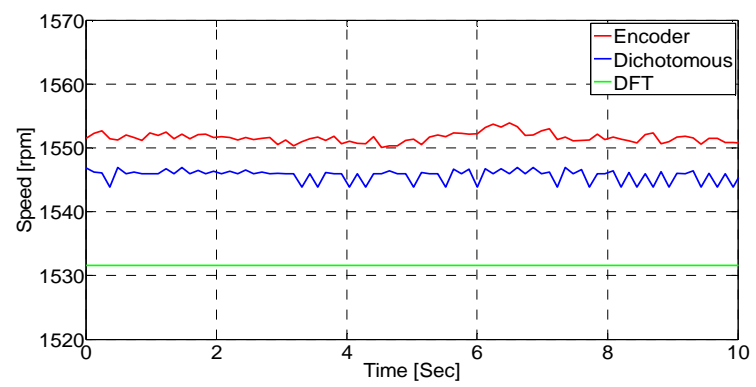

$b$

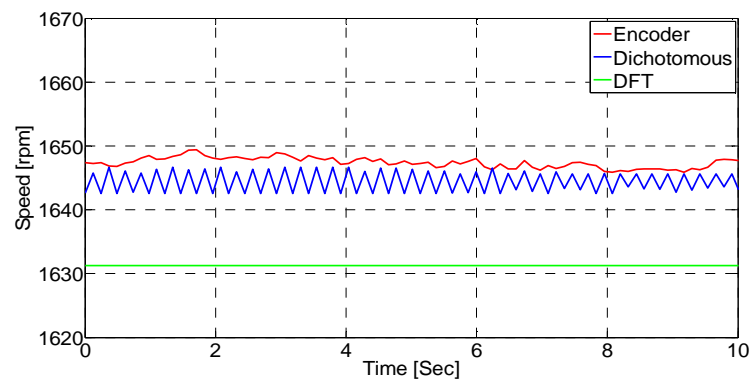

$d$

Fig. 7: Experimental results: measured and estimated speed, steady-state operation

a No-load

b $33 \%$ load

c $66 \%$ load

d $100 \%$ load

Table.1: Measured real-time estimation performance, steady-state operation

\begin{tabular}{|c|c|c|c|c|}
\hline \multirow{2}{*}{ Load [\%] } & \multicolumn{2}{|c|}{ DFT $\left(2^{8}\right)$} & \multicolumn{2}{|c|}{ Dichotomous } \\
\hline & Max Error [\%] & Average Error [\%] & Max Error [\%] & Average Error [\%] \\
\hline No-load & 1.47 & 1.38 & 0.71 & 0.50 \\
\hline $33.3 \%$ & 1.44 & 1.26 & 0.69 & 0.39 \\
\hline $66.6 \%$ & 1.20 & 1.13 & 0.50 & 0.30 \\
\hline $100 \%$ & 1.34 & 1.22 & 0.66 & 0.43 \\
\hline \multirow{2}{*}{ Load [\%] } & \multicolumn{4}{|c|}{ Dichotomous to DFT Performance Comparison } \\
\hline & \multicolumn{2}{|c|}{ Max Error [\% change] } & \multicolumn{2}{|c|}{ Average Error [\% change] } \\
\hline No-load & \multicolumn{2}{|c|}{-51.61} & \multicolumn{2}{|c|}{-63.27} \\
\hline $33.3 \%$ & \multicolumn{2}{|c|}{-52.32} & \multicolumn{2}{|c|}{-69.16} \\
\hline $66.6 \%$ & \multicolumn{2}{|c|}{-58.07} & \multicolumn{2}{|c|}{-73.49} \\
\hline $100 \%$ & \multicolumn{2}{|c|}{-50.68} & \multicolumn{2}{|c|}{-64.99} \\
\hline
\end{tabular}

4.3.3 Real-time Results for Transient Operation: Real-time speed estimation performance was assessed for a range of typical transient regimes. First, real-time tests were performed for a number of pre-programmed no-load to full-load ramps, with duration of $\approx 0.25, \approx 0.5, \approx 1, \approx 2, \approx 4, \approx 8, \approx 16$ and $\approx 32$ seconds. Illustrative 
results obtained for the fastest and slowest ramps are shown in Fig. 8; the measured estimation error in comparison with the synchronously obtained encoder measurement is presented in Table 2 for all considered ramps. The proposed algorithm delivers a maximum estimation error of less than $1 \%$ for the slower $\approx 16$ and $\approx 32 \mathrm{sec}$ ramps with a gradual maximum error increase to a sizeable $\approx 9.4 \%$ error for the rapid $\approx 0.25$ second ramp. The measured average estimation error during the transient linear speed increase ranges from $\approx 0.33 \%$ for the slowest to $\approx 5.73 \%$ for the fastest considered transient. A performance comparison between the dichotomous search algorithm and the DFT only estimation reveals a significant improvement resulting from the iterative fine search in both the maximum and the average estimation errors, ranging from $\approx 10-70 \%$ depending on the investigated ramp dynamics.
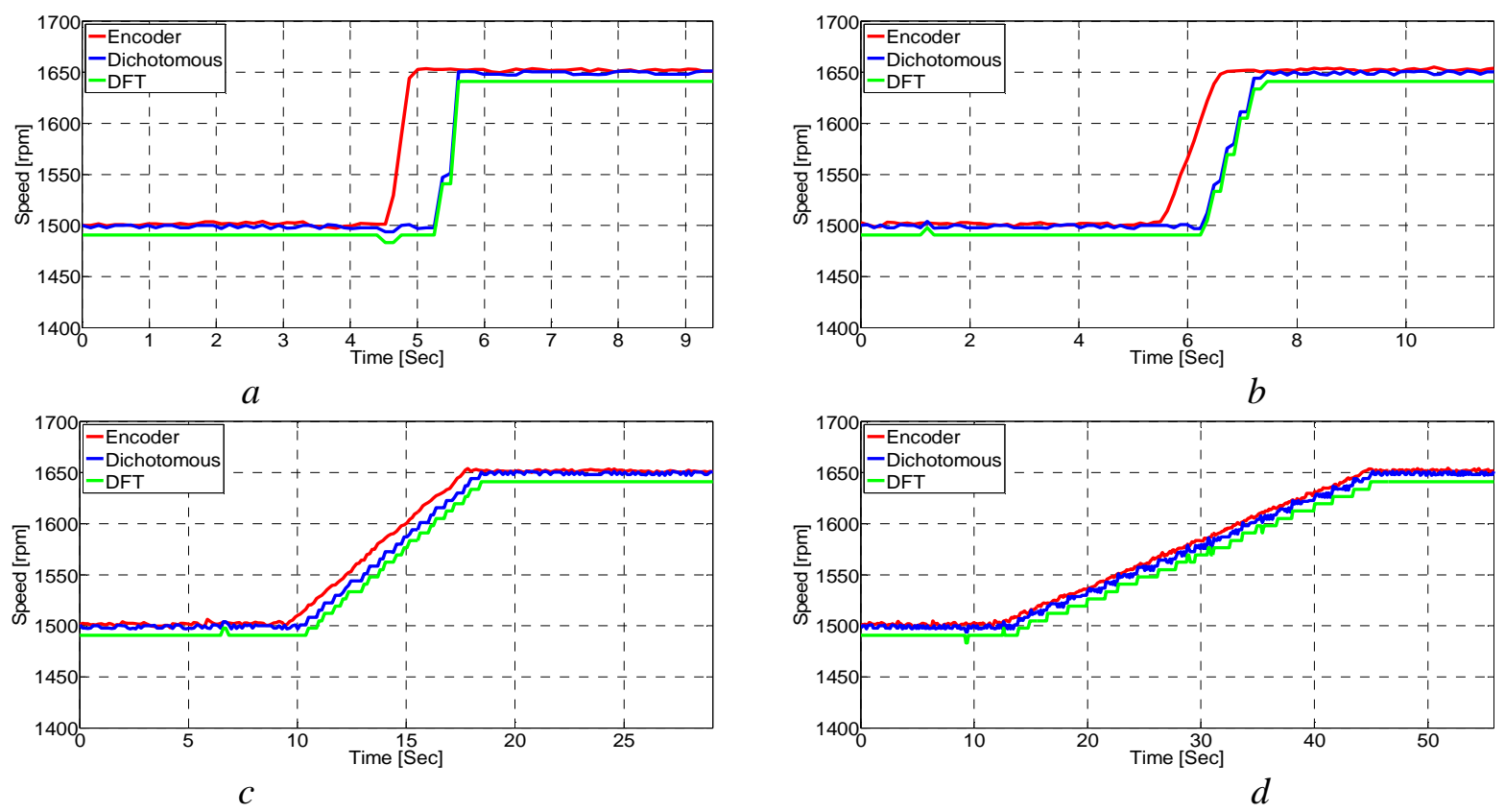

Fig. 8: Real-time speed estimation results for transient ramp conditions

a $0.25 \mathrm{sec}$ ramp

b $1 \mathrm{sec}$ ramp

c 8 sec ramp

d $32 \mathrm{sec}$ ramp 
Table.2: Measured real-time estimation performance, transient ramps

\begin{tabular}{|c|c|c|c|c|c|c|}
\hline \multicolumn{3}{|c|}{ DFT (28) } & \multicolumn{2}{c|}{ Dichotomous } & \multicolumn{2}{c|}{$\begin{array}{c}\text { Dichotomous to DFT Performance } \\
\text { Comparison }\end{array}$} \\
\hline $\begin{array}{c}\text { Ramps } \\
{[\text { [Sec] }}\end{array}$ & $\begin{array}{c}\text { Max Error } \\
{[\%]}\end{array}$ & $\begin{array}{c}\text { Average Error } \\
\text { During } \\
\text { Transient [\%] }\end{array}$ & $\begin{array}{c}\text { Max Error } \\
{[\%]}\end{array}$ & $\begin{array}{c}\text { Average Error } \\
\text { During } \\
\text { Transient [\%] }\end{array}$ & $\begin{array}{c}\text { Max Error [\% } \\
\text { change] }\end{array}$ & $\begin{array}{c}\text { Average Error } \\
\text { During Transient } \\
{[\% \text { change] }}\end{array}$ \\
\hline 32 & 1.57 & 1.17 & 0.77 & 0.33 & -51.21 & -71.35 \\
\hline 16 & 1.78 & 1.39 & 0.85 & 0.52 & -52.16 & -62.56 \\
\hline 8 & 1.96 & 1.47 & 1.32 & 0.86 & -32.27 & -41.27 \\
\hline 4 & 2.28 & 2.18 & 2.16 & 1.56 & -22.42 & -28.10 \\
\hline 2 & 4.79 & 3.26 & 3.86 & 2.40 & -19.47 & -26.30 \\
\hline 1 & 7.36 & 4.42 & 6.62 & 3.62 & -10.04 & -17.97 \\
\hline 0.5 & 10.00 & 5.38 & 9.33 & 4.55 & -6.73 & -15.32 \\
\hline 0.25 & 10.13 & 6.56 & 9.40 & 5.73 & -7.12 & -12.65 \\
\hline
\end{tabular}

To evaluate the potential of the proposed algorithm to be used in practical WRIM Type-II WT applications the test rig prime mover was controlled to provide a transient speed profile in the generating region representative of generator operating dynamics found in MW size variable-speed wind turbines [2829]. The transient profile is based on the data from a detailed WT model developed in the Supergen Wind Consortium [20,29] that uses realistic wind resource variability information as an input to a WT model to calculate the resulting generator shaft speed signal. The generated speed profile was scaled to the $-10 \%$ extended slip range of the laboratory machine to emulate the dynamics and the variable nature of wind driven WT conditions representative of those that may be encountered in WT Type-II drives. The test rig prime mover was operated in the tests to follow the scaled speed profile.

Real-time estimation performance and limitations for wind-driven representative operation were assessed in tests performed for a number of different estimation rates, ranging from $\approx 2.5$ to $\approx 15$ estimates/second. A desired estimation rate was achieved by appropriate modification of the sampling frequency to DFT window size ratio in the estimation algorithm execution on the real-time platform. The laboratory machine was operated in an identical transient profile during each estimation rate test. The obtained results showing a comparison of the estimated and measured speed signals and the corresponding absolute estimation error are shown in Fig. 9 for representative examined estimation rates; Table 3 shows the measured performance parameters for all the examined estimation rates. These demonstrate that the proposed algorithm can provide reliable real-time estimation during WRIM operation on a wind-driven representative transient profile. For all the investigated estimation rates up to and including $\approx 10$ estimates/second the measured maximum estimation error remains below $\approx 1 \%$, while the average error is lower than $\approx 0.25 \%$. As is generally expected, the real-time estimation performance is seen to gradually degrade with the increase in the estimation rate, where for the fastest examined estimation rate of $\approx 15$ estimates/second the maximum estimation error rises to $\approx 1.47 \%$ with the average estimation error of $\approx 0.46 \%$. 

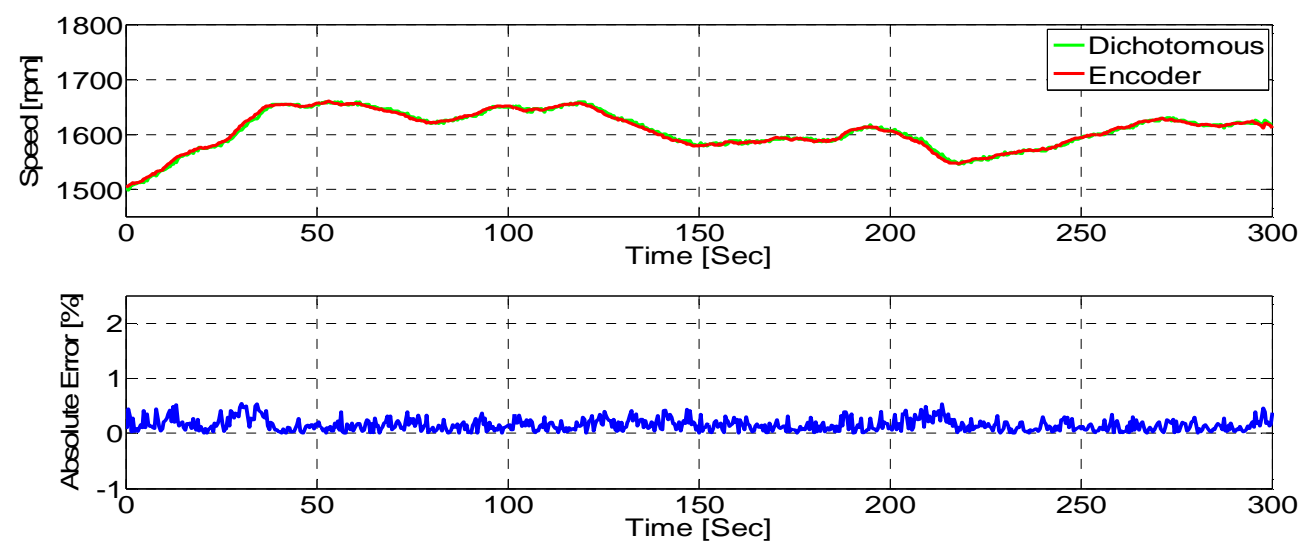

$a$
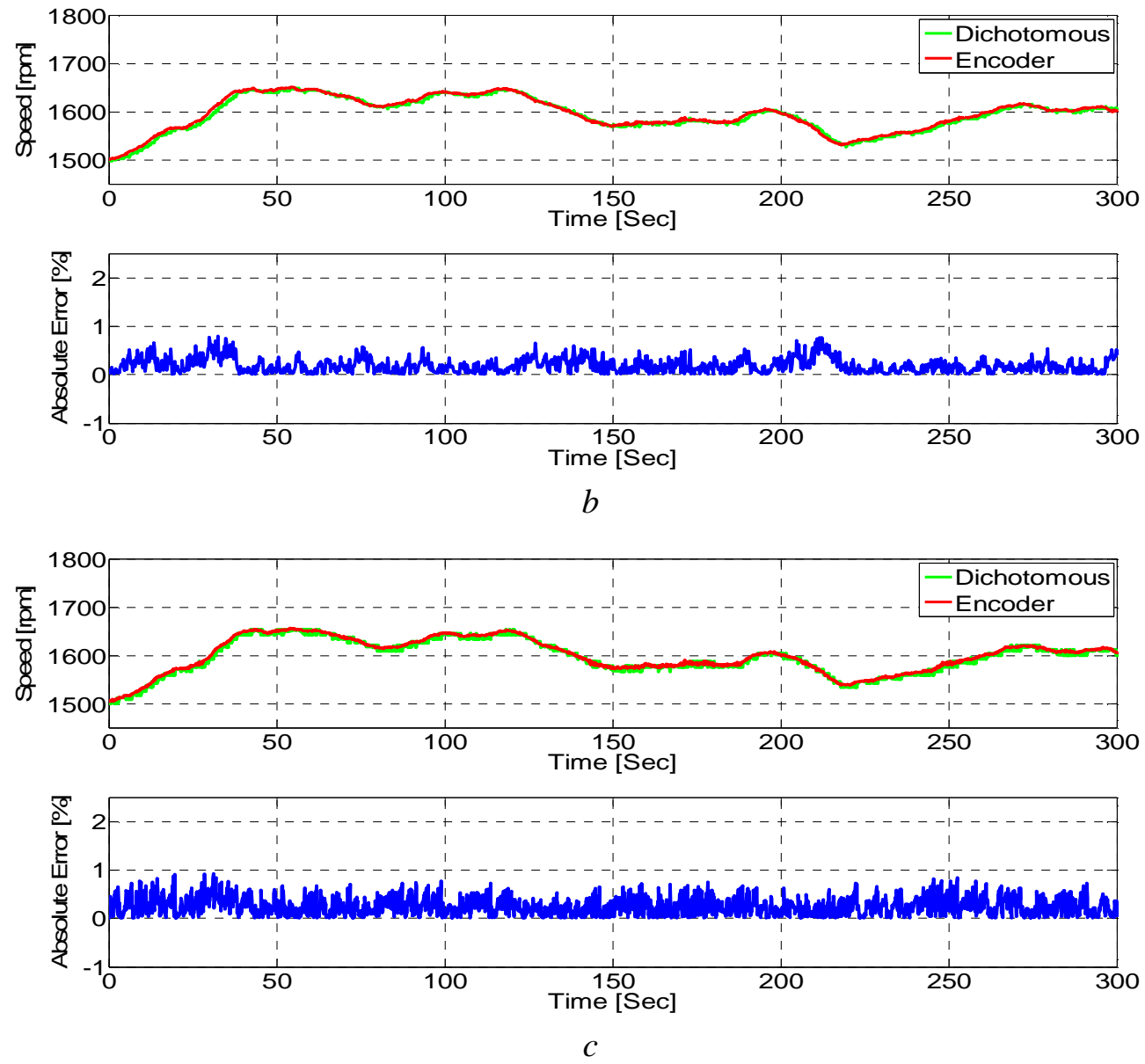

Fig. 9: Real-time speed estimation results for emulated wind driven transient conditions, -10\% slip

a 2.5 estimates per second

b 5 estimates per second

c 10 estimates per second 
Table.3: Measured real-time estimation performance, wind turbine driven profile

\begin{tabular}{|c|c|c|c|c|c|c|}
\hline $\begin{array}{c}\text { Estimates } \\
\text { persecond }\end{array}$ & $\approx \mathbf{2 . 5}$ & $\approx \mathbf{5}$ & $\mathbf{7 7 . 5}$ & $\approx \mathbf{1 0}$ & $\mathbf{\sim 1 2 . 5}$ & $\mathbf{\sim 1 5}$ \\
\hline $\begin{array}{c}\text { Maximum Absolute } \\
\text { Error [\%] }\end{array}$ & 0.55 & 0.80 & 0.87 & 0.93 & 1.29 & 1.47 \\
\hline Average Error [\%] & 0.15 & 0.19 & 0.19 & 0.25 & 0.34 & 0.46 \\
\hline
\end{tabular}

\subsection{Real-time Speed Estimation for Open-loop $\mathrm{V} / \mathrm{Hz}$ Operation}

4.4.1 Power Spectrum Analysis: The power spectrum was characterised in open-loop operation tests at zero to nominal loads and different excitation frequencies to establish the consistency of spectral content patterns with analysis presented in section 2 . This included operation at low $(f=16 \mathrm{~Hz})$ and high supply frequency $(f=50 \mathrm{~Hz})$ under no-load and full-load conditions. The measurements shown in Fig. 10a-d demonstrate that the content defined by (7) and (8) is clearly observable in the power spectrum and is interspersed by a range of variable PSU PWM harmonic effects. While other relevant components can be identified, some of which can be compromised by PWM harmonics in no-load conditions, the $k=3$ harmonic in (7) indicated in red is seen to be particularly prominent for the analysed WRIM design. Its utilisation for real-time speed estimation during open-loop operation is therefore investigated.

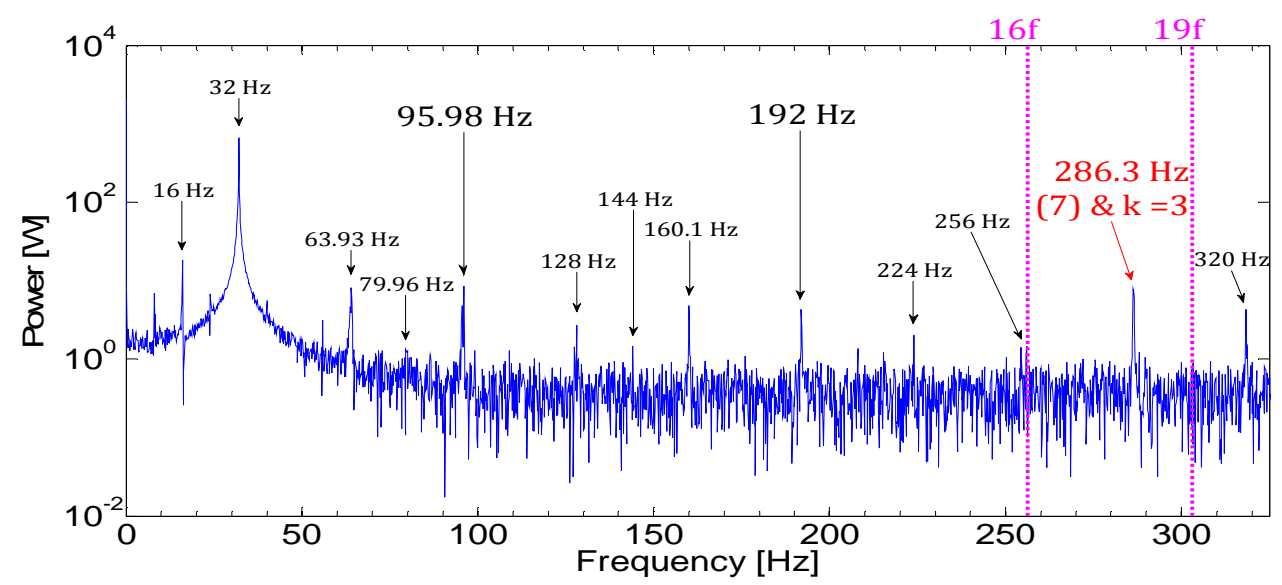

$a$ 

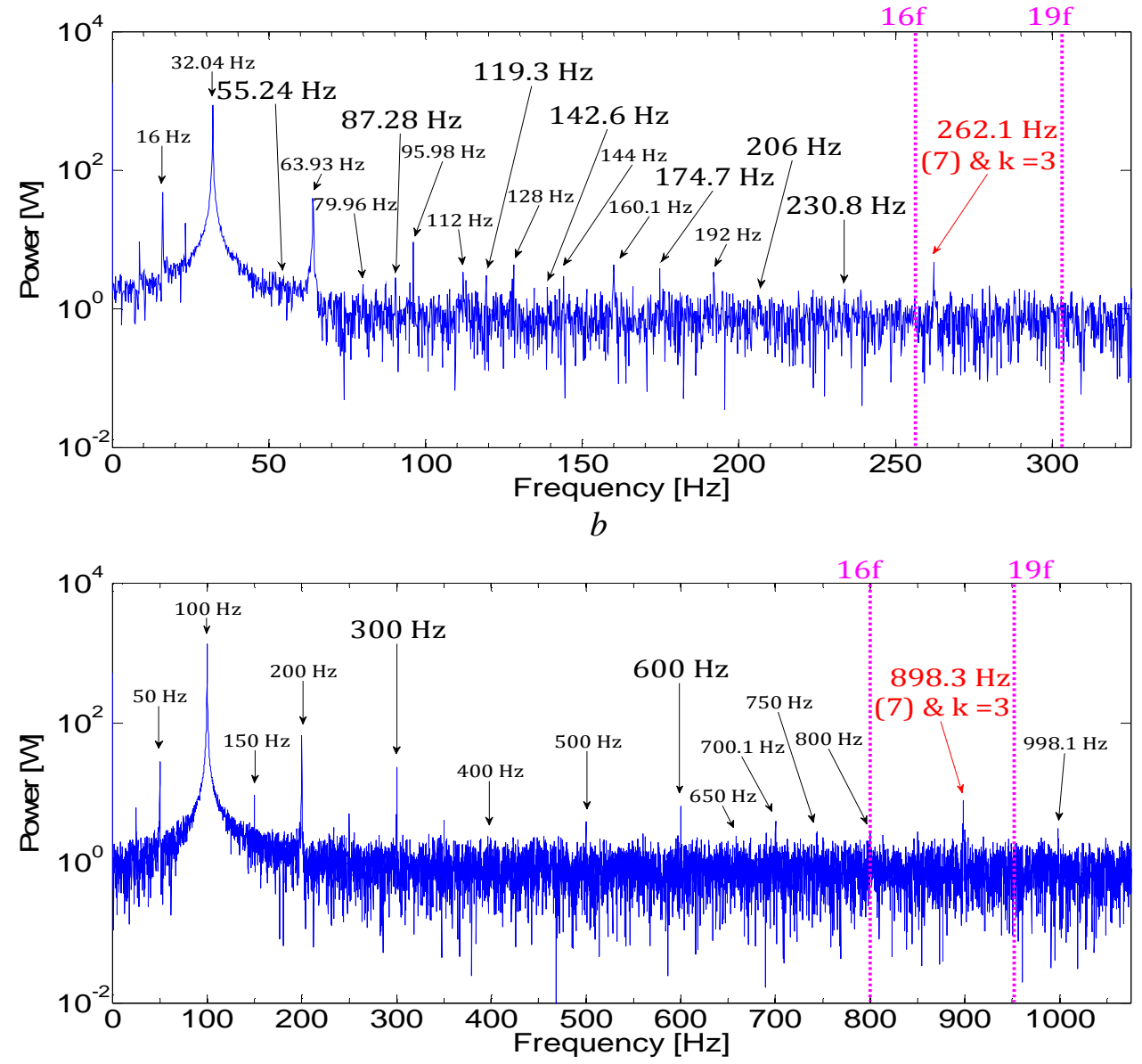

$c$

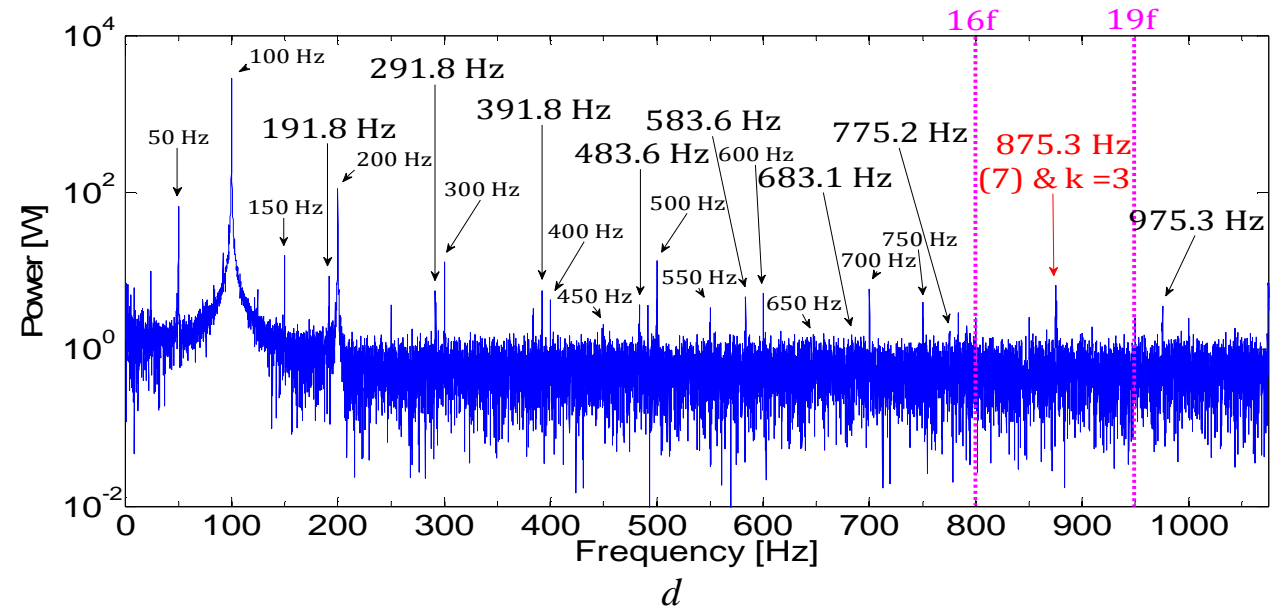

Fig. 10: Measured phase power signal spectrum, open-loop operation
a No-load, $f=16 \mathrm{~Hz}$
b $100 \%$ load, $f=16 \mathrm{~Hz}$
c No-load, $f=50 \mathrm{~Hz}$
d $100 \%$ load, $f=50 \mathrm{~Hz}$ 
4.4.2 Searched Spectral Window Identification: The power spectral frequencies containing information on rotor speed remain defined by (7) and (8) during open-loop operation. The extent of individual component's frequency change is determined by the operating range of the analysed system and will generally be significant in open-loop applications. For the investigated spectral component (i.e. $k=3$ in (7)) and the examined system where the excitation fundamental varies from $16-50 \mathrm{~Hz}$, the spectral band containing the tracked frequency can be roughly estimated from $(7)$ as $\approx 261-899 \mathrm{~Hz}$. The challenge in achieving competent SSB estimation in a wide speed range is in avoiding the interference between the tracked component and pronounced magnitude PWM harmonics inevitably present in the spectrum as any prominent PWM harmonic can compromise the performance of the tracking algorithm based on extracting the frequency maximising the spectrum. This can be effectively resolved by defining a sliding window that isolates the spectral component of interest in a narrowband spectrum $\left(\approx f_{\min }^{k}, f_{\max }^{k}\right)$ for the rated operating range. In no-load conditions $n_{r} \approx n_{s}$ allowing (7) to be rearranged:

$$
f_{\text {power }} \approx 6 k f
$$

which gives the upper window boundary spectral co-ordinate of the tracked $k=3$ harmonic in (7) as:

$$
f_{\max }^{3} \approx 18 f
$$

The window lower boundary spectral co-ordinate can be obtained by substituting the readily available information on the nominal WRIM speed at minimum supply frequency of the examined practical $\mathrm{V} / \mathrm{Hz}$ system $(16 \mathrm{~Hz}$ and $\approx 440 \mathrm{rpm}$ for the used laboratory system) into (7). For the tracked $k=3$ power harmonic of the system examined in this work this gives:

$$
f_{\min }^{3} \approx 16.5 f
$$

(10) and (11) provide spectral co-ordinates defining a sliding window that isolates the bandwidth containing and maximised by the tracked spectral component. The window boundaries are defined as a function of supply frequency, while catering for the nominal slip variation with supply frequency that is characteristic for open-loop drives [30]. Based on (10) and the investigated system operating range the sliding window boundaries are chosen as $>16 f$ and $<19 f$, as identified in Fig. 10. This boundary choice effectively eliminates the possibility of interference/crossover with PWM harmonic artefacts with the 
exception of $17 f$ and $18 f$ components shown in 4.4 .1 to be inferior to the tracked frequency and generally not expected to be pronounced in the open-loop power spectrum [30]. Extraction of speed information is simplified by the proposed sliding window application to identifying the frequency that maximises the isolated narrowband. While the proposed procedure effectively isolates the tracked frequency it also introduces the requirement for supply frequency monitoring. This however is not a significant disadvantage since the excitation frequency is regulated by the operator in open-loop control and is thus readily available. Based on this simple approach and combined with principles discussed in section 3 , the real-time estimation algorithm for open-loop operation maintains the general structure proposed in Fig. $2 \mathrm{a}$.

4.4.3 Real-time Results: The estimation performance of the proposed algorithm was evaluated in experiments on the $\mathrm{V} / \mathrm{Hz}$ controlled laboratory WRIM. The tests involved a range of different dynamics transient ramps (1-32sec duration) from minimum $(16 \mathrm{~Hz})$ to nominal $(50 \mathrm{~Hz})$ supply frequency under noload and full-load conditions. The rotor speed was synchronously estimated and measured in the tests. Representative results are shown in Fig. 11 for fastest and slowest considered ramps while Table 4 gives the measured estimation error rates for all considered transients.

The measurements demonstrate that reliable real-time estimation was achieved for the investigated test-rig's operating range limit of $\approx 1020 \mathrm{rpm}$, with the average estimation error during the fastest experimentally achievable transient of $\approx 1 \mathrm{sec}$ of $\approx 5 \%$ and a transient estimation error lower than $\approx 1.6 \%$ for all other considered ramps. The average and the maximum estimation error during steady-state open-loop operation were measured as $\approx 0.38 \%$ and $\approx 0.7 \%$, closely similar to performance levels reported in 4.3.1. While, as expected, the real-time estimation error increases with the decrease in transient duration, the presented results demonstrate that competent speed estimation can be achieved by the proposed sliding window algorithm for a wide operating speed range.

Table. 4: Measured real-time estimation performance, open loop operation

\begin{tabular}{|c|c|c|c|c|c|c|}
\hline \multicolumn{3}{|c|}{ No-load } & \multicolumn{2}{c|}{ 50\% Load } & \multicolumn{2}{c|}{ 100\% Load } \\
\hline $\begin{array}{c}\text { Ramp } \\
\text { duration } \\
{[\text { Sec] }}\end{array}$ & $\begin{array}{c}\text { Max Error } \\
{[\%]}\end{array}$ & $\begin{array}{c}\text { Average Error } \\
\text { During } \\
\text { Transient [\%] }\end{array}$ & $\begin{array}{c}\text { Max Error } \\
{[\%]}\end{array}$ & $\begin{array}{c}\text { Average Error } \\
\text { During } \\
\text { Transient [\%] }\end{array}$ & $\begin{array}{c}\text { Max Error } \\
{[\%]}\end{array}$ & $\begin{array}{c}\text { Average Error } \\
\text { During } \\
\text { Transient [\%] }\end{array}$ \\
\hline 32 & 0.83 & 0.26 & 0.91 & 0.30 & 0.84 & 0.32 \\
\hline 16 & 1.35 & 0.54 & 1.42 & 0.51 & 1.43 & 0.48 \\
\hline 8 & 2.49 & 0.94 & 2.70 & 0.91 & 2.29 & 0.96 \\
\hline 4 & 3.37 & 1.18 & 4.08 & 1.27 & 4.04 & 1.23 \\
\hline 2 & 6.07 & 1.64 & 5.65 & 1.62 & 5.69 & 1.58 \\
\hline 1 & 13.84 & 4.96 & 14.09 & 5.17 & 11.86 & 4.48 \\
\hline
\end{tabular}



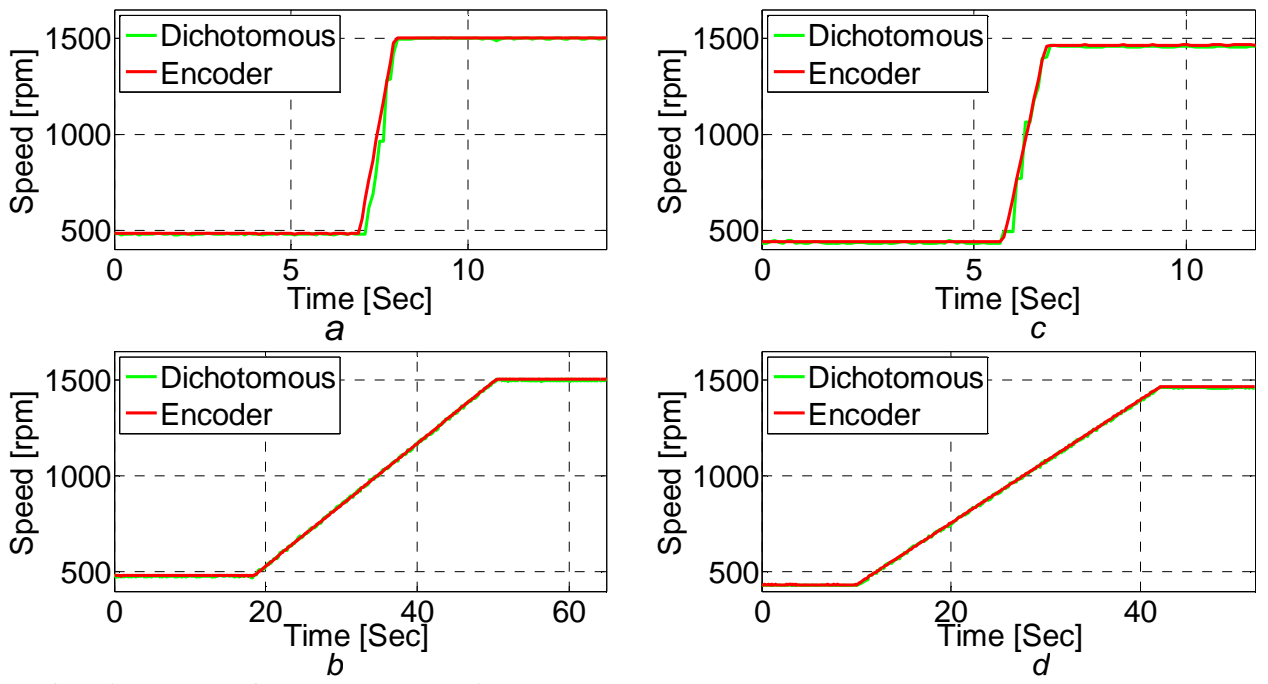

Fig. 11: Measured real-time speed estimation open-loop operation

a No-load, $1 \mathrm{sec}$

b No-load, $32 \mathrm{sec}$

c $100 \%$ load, $1 \mathrm{sec}$

d $100 \%$ load, $32 \mathrm{sec}$

\section{Conclusions}

The authors have presented an analytical study of the WRIM stator phase power signal's spectral content yielding closed form expressions that enable direct correlation of rotor speed with possible power signal spectral frequencies. The potential of the power signal for enabling SSB WRIM sensorless speed estimations schemes was then evaluated. A new estimation algorithm is reported that enables power signal spectrum based supply frequency independent speed estimation for WRIM extended-slip applications representative of those found in Type-II WT drives. The authors also present a novel, sliding window based, speed estimation scheme that enables effective wide speed range estimation from the phase power signal in WRIM open-loop controlled applications. The presented estimation algorithms are underpinned by a dichotomous search based frequency tracking method which enables an improvement in the attainable real-time estimation rate compared to the published solutions.

The proposed sensorless schemes have been assessed and validated in real-time laboratory experiments on a practical WRIM system. While, as expected, accuracy limitations exist for very rapid transient regimes, the proposed algorithms have been demonstrated to deliver reliable real-time estimation for open-loop controlled and extended slip WRIM operation at rates of up to $\approx 10$ estimates/second and for lower dynamics representative of those found in industrial applications. The presented material is based on utilising a particular power spectral component identified in tests as optimal for enabling sensorless 
estimation schemes for the investigated industrial WRIM design; while other suitable components exist the utilisation of these is not assessed in this work for the sake of brevity. The reported principles however enable the development and application of the proposed methods on alternative practical WRIM systems operating in open-loop or extended slip mode.

\section{References}

[1] Hurst, K. D., Habetler, T. G.: 'Sensorless speed measurement using current harmonic spectral estimation in induction machine drives', IEEE Transactions on Power. Electronics., 1996, pp.66-73.

[2] Nandi, S., Ahmed, S., Toliyat, H. A., et al.: 'Selection criteria of induction machines for speedsensorless drive applications', IEEE Transactions on Industry Applications., 2003, 39, (3), pp.704-712.

[3] Hurst, K. D., Habetler, T. G.: 'A comparison of spectrum estimation techniques for sensorless speed detection in induction machines', IEEE Transactions on Industry Applications., 1997, 33, (4), pp.898-905. [4] Blasco-Glimenez, R., Asher, G. M., Sumner, M., et al.: 'Performance of FFT-rotor slot harmonics speed detector for sensorless induction motor drives', IEE Proceedings on Electric Power Applications., 1996, 43, (3), pp.258-268.

[5] Dongfeng, S., Unsworth, P. J., Gao, R. X.: 'Sensorless speed measurement of induction motor using Hilbert transform and interpolated fast Fourier transform', IEEE Transactions on Instrumentation and Measurement., 2006, 55, (1), pp.290,299.

[6] Lacerda Silva, W., Nogueira Lima, A. M., Oliveira, A.: 'Speed Estimation of an Induction Motor Operating in the Nonstationary Mode by Using Rotor Slot Harmonics', IEEE Transactions on Instrumentation and Measurement., 2015, 64, (4), pp.984-994.

[7] Orlowska-Kowalska, T., Dybkowski, M.: 'Stator-Current-Based MRAS Estimator for a Wide Range Speed-Sensorless Induction-Motor Drive', IEEE Transactions on Industrial Electronics., 2010, 57, (4), pp.1296-1308.

[8] Gadoue, S. M., Giaouris, D., Finch, J. W.: 'Stator current model reference adaptive systems speed estimator for regenerating-mode low-speed operation of sensorless induction motor drives', IET Electric Power Applications., 2013, 7, 7, pp.597-606.

[9] Williamson, S., Djurovic, S.: 'Origins of stator current spectra in DFIGs with winding faults and excitation asymmetries', Proc. IEEE Int. Conf. Electric Machines and Drives, May 2009, pp.563-570.

[10] Lindholm, M., Rasmussen, T. W.: 'Harmonic analysis of doubly fed induction generators', Proc. Int. Conf. Power Electronics and Drive Systems, November 2003, pp.837-841.

[11] Larose, C., Gagnon, R., Prud Homme, et al.: 'Type-III Wind Power Plant Harmonic Emissions: Field Measurements and Aggregation Guidelines for Adequate Representation of Harmonics', IEEE Transactions on Sustainable Energy., 2013, 4, 3, pp.797-804.

[12] Crabtree, C. J., Djurovic, S., Tavner, P. J, et al.: 'Condition monitoring of a wind turbine DFIG by current or power analysis', Proc. Int. Conf. Power Electronics, Machines and Drives, April 2010, pp.1-6.

[13] Poljugan, A., Kolonic, F., Slutej, A.: 'The Impact of the System Operating Point on the Accuracy of the AC Slip-Ring Motor Speed Estimation,'Power Electronics and Motion Control Conference EPEPEMC 2006, Slovenia 2006.

[14] ABB., 'ASTAT crane motion controller', Manual versionAST10_054, ABB automation system, 2007, pp. 1-365.

[15] Wind Generator Modeling Group.: 'Standard wind turbine-generator models', Proc. Int. Conf. UWIG Modeling and Interconnection User Group Meeting, Oklahoma City, OK, USA, October 2006. 
[16] Li, H., Chen, Z.: 'Overview of different wind generator systems and their comparisons', IET Renewable Power Generation., 2008, 2, (2), pp.123-138.

[17] Drury.B.: 'The control techniques drives and controls handbook', (IET, $2^{\text {nd }}$ edn. 2009)

[18] Aboutanios, E.: 'A modified dichotomous search frequency estimator', IEEE Transactions on Signal Processing Letters., 2004, 11, (2), pp.186-188.

[19] Zakharov, Y. V., Tozer, T. C.: 'Frequency estimator with dichotomous search of periodogram peak', IEE Electronics Letters., 1999, 35, (19), pp.1608-1609.

[20] Tshiloz, K., S. Djukanović., Djurović, S.: 'Real-Time Sensor-Less Speed Estimation in Wound Rotor Induction Machines using a Dichotomous Search Algorithm', Proc. Of IEEE Int. Conf. Electric Machines and Drives, Idaho, USA, May 2015, pp.1036-1042.

[21] Djurović, S., Vilchis-Rodriguez, D.S., Smith, A.C.: 'Supply Induced Interharmonic Effects in Wound Rotor and Doubly-Fed Induction Generators', IEEE Transactions on Energy Conversion., 2015, PP, (99), pp.1-12.

[22] Djurović, S., Williamson, S.: 'Influence of supply harmonic voltages on DFIG stator current and power spectrum', Proc. Int. Conf. Electrical Machines, September 2010, pp.1-6.

[23] Bayliss, C., Hardy, B., Baylis, C. R.: 'Transmission and Distribution Electrical Engineering', (Newness, Oxford, $4^{\text {th }}$ edn. 2012).

[24] Djurović, S., Williamson, S., Renfrew, A.: 'Dynamic model for doubly-fed induction generators with unbalanced excitation, both with and without winding faults', IET Electric Power Applications., 2009, 3, 3, pp.171-177.

[25] Djurović, S., Williamson, S.: 'A coupled circuit model for a DFIG operating under unbalanced conditions', Proc. Int. Conf. Electrical Machines, Portugal, September 2000, pp. 1-6.

[26] 'Voltage Characteristics of the Electricity Supplied by Public Distribution Systems', European/British Standard EN 50160, 2010, pp. 1-12.

[27] Ackermann, T.: 'Wind Power in Power System' (John Wiley \& Sons, $2^{\text {nd }}$ edn. 2012).

[28] Djurovic, S., Crabtree, C J., Tavner, P.J., et al.: 'Condition monitoring of wind turbine induction generators with rotor electrical asymmetry', IET Renewable Power Generation., 2012, 6, (4), pp.207-216.

[29] Wenxian, Y., Tavner, P. J, Crabtree, C. J., et al.: 'Cost-Effective Condition Monitoring for Wind Turbines', IEEE Transactions on Industrial Electronics., 2010, 57, 1, pp.263-271.

[30] Mohan, Ned., Underland, Tore., Robbins, P Williams.: 'Power Electronics', (John Wiley \& Sons, $3^{\text {rd }}$ edn. 2003). 